\title{
Treatment with tenofovir alafenamide fumarate worsens the lipid profile of HIV-infected patients versus treatment with tenofovir disoproxil fumarate, each coformulated with elvitegravir, cobicistat, and emtricitabine
}

\author{
Purificación Cid-Silva ${ }^{1,2}$ Noelia Fernández-Bargiela ${ }^{2}$ Luis Margusino-Framiñán ${ }^{1,2}$ \\ Vanesa Balboa-Barreiro ${ }^{3}$ Álvaro Mena-De-Cea ${ }^{1,4}$ Soledad López-Calvo ${ }^{4}$ Pilar \\ Vázquez-Rodríguez ${ }^{4}$ Isabel Martín-Herranz ${ }^{2}$ Enrique Míguez-Rey ${ }^{1}$ Eva Poveda $^{5}$ \\ Ángeles Castro-Iglesias ${ }^{1,4}$ \\ ${ }^{1}$ Division of Clinical Virology, Biomedical Research Institute of A Coruña (INIBIC)-Universitary Hospital of \\ A Coruña (CHUAC), SERGAS, University of A Coruña (UDC), A Coruña, Spain. \\ ${ }^{2}$ Service of Pharmacy, Universitary Hospital of A Coruña (CHUAC), SERGAS, A Coruña, Spain. \\ ${ }^{3}$ Clinical Epidemiology and Biostatistics Unit, Biomedical Research Institute of A Coruña (INIBIC)- \\ Universitary Hospital of A Coruña (CHUAC), SERGAS, University of A Coruña (UDC), A Coruña, Spain. \\ ${ }^{4}$ Service of Infectious Internal Medicine, Universitary Hospital of A Coruña (CHUAC), SERGAS, A Coruña, \\ Spain. \\ ${ }_{5}^{5}$ Group of Virology and Pathogenesis, Galicia Sur Health Research Institute (IIS Galicia Sur)-Complexo \\ Hospitalario Universitario de Vigo, SERGAS-UVigo, Vigo, Spain.
}

\begin{abstract}
Two elvitegravir/cobicistat-based therapies combined with emtricitabine/tenofovir disoproxil fumarate $(\mathrm{EVG} / \mathrm{c} / \mathrm{FTC} / \mathrm{TDF})$ or emtricitabine/tenofovir alafenamide fumarate (EVG/c/FTC/TAF) are currently available for HIV patients. This study evaluated the modifications in the lipid profile of patients who received these treatments in the last three years at our institution. A retrospective observational study in HIV-infected patients who received EVG/c/FTC/TDF or EVG/c/FTC/TAF from January 2015 to January 2018 at a reference hospital in northwestern Spain was carried out. Epidemiological, clinical and immunovirological data were recorded. A statistical analysis was performed using SPSS software. A total of $384 \mathrm{EVG} / \mathrm{c}-\mathrm{based}$ therapies were initiated during the study period, $151 \mathrm{EVG} / \mathrm{c} / \mathrm{FTC} / \mathrm{TDF}$ and $233 \mathrm{EVG} / \mathrm{c} / \mathrm{FTC} / \mathrm{TAF}$. A significantly negative influence in all the lipid profile parameters in experienced patients and total cholesterol (TC), and LDL-C in naïve patients were observed after 48 weeks of treatment with EVG/c/FTC/TAF, while these parameters remained stable in the EVG/c/FTC/TDF group. During follow-up, a greater proportion of patients had lipid levels above the normal range $(63.1 \% \mathrm{TC}, 56.2 \% \mathrm{LDL}-\mathrm{C})$ and new lipid-modifying drugs were prescribed $(11.9 \%)$ in the EVG/c/FTC/TAF group. The number of cardiovascular risk factors (OR 1.66 [95\% CI 1.01-2.72]; $P=0.043$ ) was recognised as an independent predictor of lipid-lowering prescription for patients treated with both $\mathrm{EVG} / \mathrm{c} / \mathrm{FTC} / \mathrm{TDF}$ and $\mathrm{EVG} / \mathrm{c} / \mathrm{FTC} / \mathrm{TAF}$. For patients treated with $\mathrm{EVG} / \mathrm{c} / \mathrm{FTC} / \mathrm{TAF}$, the mean total cholesterol to HDL ratio in the first 48 weeks of the study treatment was associated with a higher likelihood of lipid-lowering prescription in multivariate analysis (OR 1.6 [95\% CI 1.12-2.52]; $P=0.011$ ). Significant changes in lipid profile have been observed in patients who have received $\mathrm{EVG} / \mathrm{c} / \mathrm{FTC} / \mathrm{TAF}$. It was necessary to prescribe almost twice the number of lipid-lowering drugs to patients who received $\mathrm{EVG} / \mathrm{c} / \mathrm{FTC} / \mathrm{TAF}$ (11.9\%) vs EVG/c/FTC/TDF (4.7\%).
\end{abstract}

Keywords

Adverse events, dyslipidemia, HIV, tenofovir alafenamide furamate, tenofovir disoproxil fumarate 


\section{INTRODUCTION}

Antiretroviral therapy (ART) has dramatically changed the prognosis of human immunodeficiency virus (HIV) infection, with a significant decrease in morbidities and mortalities related to AIDS. The availability of these drugs has been a key factor in prolonging the lives of those infected, whose life expectancy has increased from less than 2 years after AIDS illness in the past two decades in patients who receive optimum treatment in the present, approaching that of the general population. ${ }^{1}$ However, long-term use of ART is not free from side effects, and has been related to worsening observed in glucose and lipid values and associated with the risk of developing atherosclerosis, coronary artery disease, and increased incidence of acute myocardial infarction. ${ }^{2,3}$ In addition, the ageing population has brought about an increase in the incidence of comorbidities such as dyslipidaemia, hypertension and diabetes, ${ }^{4}$ while there is also a high rate of HIV-smoking patients. ${ }^{5}$ Furthermore, HIV infection leads to a series of immunological changes (ie low CD4/CD8 ratio, low T cell proliferative potential, reduced T cell repertoire, increased IL-6, increased $\mathrm{T}$ cell activation, reduced thymus function, reduced response to vaccines ${ }^{6}$ ) due to the baseline immune activation and persistent chronic inflammation caused by the virus, which can affect a diverse range of organs, thus leading to cardiovascular damage. Taking the above into account, it is clear that cardiovascular disease has now become one of the main causes of death in HIV patients. ${ }^{2,7}$ Therefore, there is a great deal of concern about the cardiovascular health of HIVinfected individuals in the long term.

National and international guidelines for the initial treatment of HIV-infected patients ${ }^{8-10}$ recommend the use of two nucleoside analogue reverse transcriptase inhibitors (NRTIs) plus a third active drug: an integrase strand transfer inhibitor (INSTI), a non-nucleoside reverse transcriptase inhibitor (NNRTI), or a boosted protease inhibitor (PI).

Among the NRTIs, tenofovir disoproxil fumarate (TDF) was approved by the American and European drugs regulatory authorities and was available for HIV treatment in 2002. Since its approval, this drug has been included in most recommended regimens and has been the most widely used NRTI for many years based on its established high efficacy and generally good tolerance, as demonstrated in clinical trials and real-life studies. ${ }^{11-15}$

Furthermore, using TDF-containing NRTI regimens has improved lipid parameters, supporting a lipid-lowering effect of TDF. ${ }^{16-18}$ Despite its favourable characteristics, TDF can have clinically significant renal toxic effects and lead to a greater decline in bone mineral density (BMD) relative to some other NRTIs, attributed to high circulating plasma levels of tenofovir. ${ }^{19-21}$

Tenofovir alafenamide fumarate (TAF), a novel oral prodrug of tenofovir, was first approved in 2015 combined with emtricitabine, elvitegravir and cobicistat (EVG/c/FTC/TAF). TAFcontaining regimens have less of an impact on measures of renal and bone safety compared with TDF-containing regimens; this is believed to be due to the tenofovir alafenamide's reduced dose, which is enough to reach an optimal intracellular concentration of the active metabolite tenofovirdiphosphate, and consequently a significant reduction in plasma tenofovir concentrations. ${ }^{19-21}$ Clinical guidelines hold that the use of the regimens containing TAF is preferred over those containing TDF, due to the greater efficacy and better tolerance profile demonstrated in clinical trial patients. ${ }^{8-10}$

Variations in lipid levels in pivotal clinical trials of EVG/c/FTC/TAF were minimal, without clinical or statistical significance. ${ }^{19,21-25}$ The present study evaluated modifications in the lipid profile in a large real-world cohort of naïve and treatment-experienced HIV patients who had received $\mathrm{EVG} / \mathrm{c} / \mathrm{FTC} / \mathrm{TAF}$ or elvitegravir/cobicistat/emtricitabine/tenofovir disoproxil fumarate (EVG/c/FTC/TDF). 


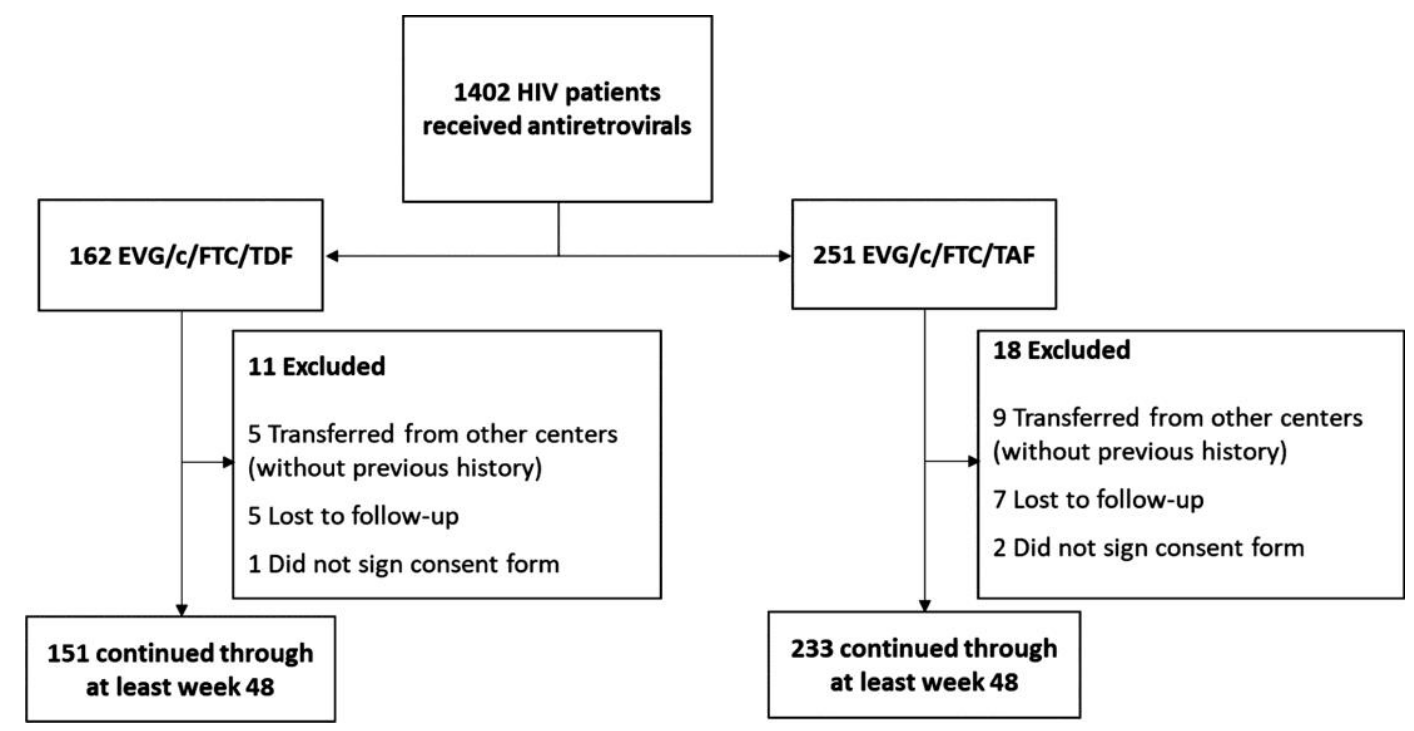

Figure 1 Design of the study

\section{MATERIALS AND METHODS}

This was an observational study in adult HIV-1-infected patients who started antiretroviral therapy with EVG/c/FTC/TDF or EVG/c/FTC/TAF from 1 January 2015 to 31 January 2018 at a reference hospital in northwestern Spain. The selection of antiretroviral treatments for each patient was made based on clinical criteria and recommendations of the national clinical practice guidelines of each year, with no intervention. Only those patients who had signed the informed consent document and had at least one follow-up visit were included. Those patients participating in clinical trials or who had been transferred from other centres (hospitals or penitentiaries) using the study drugs were excluded from the study. The study was conducted in accordance with the Basic \& Clinical Pharmacology \& Toxicology policy for experimental and clinical studies. ${ }^{26}$ Epidemiological, clinical, immunovirological data and information regarding ART were retrospectively recorded. The time of follow-up was defined as spanning from the day of $\mathrm{EVG} / \mathrm{c} / \mathrm{FTC} / \mathrm{TDF}$ or EVG/c/FTC/TAF initiation until the day of discontinuation or the last clinical analysis in the follow-up period. The basal lipid profile was compared with that at 48 weeks after receiving the study ART. The "Division of AIDS Table for Grading the Severity of Adult and Pediatric Adverse Events, Version 2.0"27 was considered for assessing the severity of laboratory abnormalities. Presence of the following cardiovascular risk factors was recorded: dyslipidaemia (total cholesterol $\geq 200 \mathrm{mg} / \mathrm{dL}$, triglycerides $\geq 150 \mathrm{mg} / \mathrm{dL}$, LDL-C $\geq 130 \mathrm{mg} / \mathrm{dL}$ and/or treatment with lipid-lowering agents registered in medical records), arterial hypertension (registered in medical records and/or antihypertensive treatment), diabetes mellitus (registered in medical records and/or treatment with oral glucose-lowering agents or insulin) and smoking (current smoker, ex-smoker and non-smoker). In terms of adherence to antiretrovirals (according to hospital pharmacy records) or lipid-lowering drugs (according to dispensations registered in electronic clinical history), $\geq 90 \%$ was considered optimal. 
A statistical analysis was performed using SPSS v.19. software. Group differences were compared using the Pearson $\chi^{2}$ or Fisher's exact test and Student's $t$-test or the Mann-Whitney $U$ test, respectively, for categorical and continuous variables. Repeated measurements were compared using a paired Student's $t$-test or Wilcoxon's signed-rank test. Univariate analyses were performed using all the covariates. Multivariate Cox regression analysis of the statistically significant univariate covariates as well as the clinically relevant covariates was performed to identify risk factors for lipid-lowering drug prescriptions. $P$-values of 0.05 or less were considered statistically significant.

\section{RESULTS}

\subsection{Baseline characteristics of the study population}

A total of $384 \mathrm{EVG} / \mathrm{c}$-based therapies were initiated within the observation period at our institution: 151 patients started EVG/c/FTC/TDF and 233 EVG/c/FTC/TAF (Figure 1). Baseline characteristics were similar between groups. The majority of patients who received EVG/c/FTC/TDF and EVG/c/FTC/TAF were men, with a median age of 46 years, and they also received stable antiretroviral therapy (experienced). The most common acquisition risk factor for HIV infection was related to sexual activity for both groups. The immunovirological characteristics in naïve and experienced patients were similar between groups. There was a greater percentage of Caucasians in the EVG/c/FTC/TDF group and a higher rate of RNA-HIV basal $<50$ copies/mL in the EVG/c/FTC/TAF group (Table 1). 
Table 1. Baseline characteristics of the study population

\begin{tabular}{|c|c|c|c|}
\hline Variables & $\mathrm{EVG} / \mathrm{c} / \mathrm{FTC} / \mathrm{TDF}(n=151)$ & $\mathrm{EVG} / \mathrm{c} / \mathrm{FTC} / \mathrm{TAF}(n=233)$ & $P$-value \\
\hline \multicolumn{4}{|l|}{ Demographic-epidemiological } \\
\hline Male $(\%)$ & 84.8 & 75.5 & 0.3566 \\
\hline Age (years $\pm \mathrm{SD})$ & $45.3 \pm 9.1$ & $46.5 \pm 10.4$ & 0.2455 \\
\hline $20-40$ years $(\%)$ & 30.5 & 27.0 & 0.7224 \\
\hline $41-60$ years $(\%)$ & 64.2 & 66.5 & \\
\hline$>60$ years $(\%)$ & 5.3 & 6.4 & \\
\hline \multicolumn{4}{|l|}{ HIV risk factor } \\
\hline $\operatorname{MSM}(\%)$ & 43.0 & 36.5 & 0.2326 \\
\hline Heterosexual (\%) & 26.5 & 34.3 & \\
\hline $\operatorname{IDU}(\%)$ & 27.2 & 23.6 & \\
\hline Unknown (\%) & 3.3 & 5.6 & \\
\hline \multicolumn{4}{|l|}{ Ethnic origin } \\
\hline Caucasian $(\%)$ & 93.4 & 83.7 & 0.0051 \\
\hline Latin $(\%)$ & 6.6 & 13.3 & \\
\hline Black $(\%)$ & 0.0 & 3.0 & \\
\hline \multicolumn{4}{|l|}{ Co-infections } \\
\hline Anti-HCV positive $(\%)$ & 23.2 & 23.2 & 0.8358 \\
\hline HBsAg positive (\%) & 4.6 & 3.0 & 0.5792 \\
\hline HIV status in naïve patients (\%) & 21.9 & 18.9 & 0.4777 \\
\hline Mean CD4 (cells $/ \mu \mathrm{L} \pm \mathrm{SD})$ & $435.6 \pm 288.4$ & $452.1 \pm 379.3$ & 0.8351 \\
\hline Mean RNA-HIV (log copies/mL \pm SD) & $4.8 \pm 0.7$ & $4.6 \pm 0.9$ & 0.4798 \\
\hline HIV status in experienced patients & 78.1 & 81.1 & \\
\hline Mean CD4 (cells $/ \mu \mathrm{L} \pm \mathrm{SD})$ & $607.2 \pm 288.8$ & $619.0 \pm 319.0$ & 0.7441 \\
\hline RNA-HIV basal $(\% \mathrm{VL}<50$ copies/mL) & 76.3 & 85.7 & 0.0358 \\
\hline \multicolumn{4}{|l|}{ Cardiovascular risk factors } \\
\hline \multicolumn{4}{|l|}{ Smoking history } \\
\hline Former $(\%)$ & 12.6 & 13.3 & 0.8373 \\
\hline Current $(\%)$ & 46.4 & 41.2 & 0.3191 \\
\hline Hypertension (\%) & 9.3 & 12.4 & 0.3352 \\
\hline Diabetes $(\%)$ & 4.6 & 5.6 & 0.6844 \\
\hline Obesity $(\%)$ & 4.6 & 3.9 & 0.9133 \\
\hline Dyslipidaemia & 23.2 & 27.5 & 0.3480 \\
\hline \multicolumn{4}{|l|}{ Lipid-lowering agents } \\
\hline Statins $(\%)$ & 7.3 & 12.4 & 0.1058 \\
\hline Ezetimibe (\%) & 0.6 & 0.8 & 1.000 \\
\hline Fibrates $(\%)$ & 2.6 & 2.1 & 0.7426 \\
\hline
\end{tabular}

HDL-C: HDL Cholesterol; IDU: intravenous drug use; LDL-C: LDL Cholesterol; MSM: men who have sex with men; TC: Total Cholesterol; TG: Triglycerides; VL: viral load.

In both groups, there was a high percentage of patients with at least one cardiovascular risk factor $(71.5 \%$ in EVG/c/FTC/TDF vs $70.8 \%$ of the patients in EVG/c/FTC/TAF, $P=0.9322)$. The basal cardiovascular risk factors were similar in both the EVG/c/FTC/TDF and EVG/c/FTC/TAF treatment groups. No differences were seen in the ratio of basal lipid-lowering agent prescriptions. 


\subsection{Lipid profile variations in EVG/c/FTC/TDF group}

Experienced patients in the EVG/c/FTC/TDF treatment group did not show significant variation in their lipid profile when we compared the basal lipid values with those at 48 weeks after the start of the study treatment. Only in HIV treatment-naïve patients, excluding those with lipid-lowering treatment prescription (either prior $[n=1]$ or during follow-up [ $n=2]$ lipidlowering prescription), statistically significant differences were observed in total cholesterol (TC; $159.8 \pm 31.9$ vs $183.0 \pm 28.6, P=0.007)$ and HDL-C $(37.1 \pm 13.8$ vs $43.5 \pm 14.0, P=0.005)$. The rate of patients with values above the normal range before and 48 weeks after prescription of EVG/c/FTC/TDF was similar (Table 2). 
Table 2. Changes in lipid profiles after 48 weeks of study treatment excluding patients with lipid-lowering treatment prescription

\begin{tabular}{|c|c|c|c|c|c|c|}
\hline & \multicolumn{3}{|c|}{$\mathrm{EVG} / \mathrm{c} / \mathrm{FTC} / \mathrm{TDF}(n=130)$} & \multicolumn{3}{|c|}{$\mathrm{EVG} / \mathrm{c} / \mathrm{FTC} / \mathrm{TAF}(n=179)$} \\
\hline & Basal & WK48 & $P$-value & Basal & WK48 & $P$-value \\
\hline \multicolumn{7}{|l|}{ Naïve patients } \\
\hline \multicolumn{7}{|l|}{ Lipid levels (mean \pm SD) } \\
\hline $\mathrm{TG} \mathrm{mg} / \mathrm{dL}$ & $115.5 \pm 56.4$ & $143.0 \pm 106.6$ & 0.795 & $125.8 \pm 59.0$ & $127.7 \pm 69.7$ & 0.758 \\
\hline $\mathrm{TC} \mathrm{mg} / \mathrm{dL}$ & $159.8 \pm 31.9$ & $183.0 \pm 28.6$ & 0.007 & $173.3 \pm 44.8$ & $209.6 \pm 35.5$ & $<0.001$ \\
\hline LDL-C mg/dL & $100.5 \pm 22.0$ & $112.4 \pm 21.1$ & 0.074 & $109.7 \pm 40.5$ & $132.1 \pm 31.3$ & 0.027 \\
\hline $\mathrm{HDL}-\mathrm{C} \mathrm{mg} / \mathrm{dL}$ & $37.1 \pm 13.8$ & $43.5 \pm 14.0$ & 0.005 & $43.0 \pm 8.2$ & $53.3 \pm 12.6$ & $<0.001$ \\
\hline TC:HDL-C ratio & $4.6 \pm 1.1$ & $4.4 \pm 1.0$ & 0.570 & $4.1 \pm 0.9$ & $4.1 \pm 1.1$ & 0.088 \\
\hline LDL-C/HDL-C ratio & $2.9 \pm 0.8$ & $2.7 \pm 0.7$ & 0.691 & $2.5 \pm 0.9$ & $2.6 \pm 0.9$ & 0.227 \\
\hline \multicolumn{7}{|l|}{ Lipid levels out range (\%) } \\
\hline $\mathrm{TG}(\geq 150 \mathrm{mg} / \mathrm{dL})$ & 28.0 & 28.6 & 0.7750 & 32.4 & 23.5 & 0.5693 \\
\hline $\mathrm{TC}(\geq 200 \mathrm{mg} / \mathrm{dL})$ & 12.0 & 19.0 & 0.8020 & 29.7 & 61.8 & 0.0135 \\
\hline LDL-C $(\geq 130 \mathrm{mg} / \mathrm{dL})$ & 8.7 & 9.5 & 0.6676 & 28.1 & 57.6 & 0.0318 \\
\hline TC:HDL-C ratio ( $\geq 4.5$ for men; $\geq 4.0$ for women) & 52.2 & 47.6 & 1.000 & 46.9 & 36.4 & 0.5432 \\
\hline LDL-C:HDL-C ratio ( $\geq 3.0$ for men; $\geq 2.5$ for women) & 43.5 & 38.1 & 0.9555 & 34.4 & 42.4 & 0.6804 \\
\hline \multicolumn{7}{|l|}{ Experienced patients } \\
\hline \multicolumn{7}{|l|}{ Lipid levels (mean \pm SD) } \\
\hline $\mathrm{TG} \mathrm{mg} / \mathrm{dL}$ & $114.8 \pm 58.0$ & $121.6 \pm 67.9$ & 0.864 & $120 \pm 64.2$ & $148.9 \pm 123.5$ & $<0.001$ \\
\hline $\mathrm{TC} \mathrm{mg} / \mathrm{dL}$ & $176.6 \pm 36.1$ & $177.5 \pm 36.6$ & 0.110 & $179.9 \pm 35.8$ & $208.9 \pm 38.0$ & $<0.001$ \\
\hline LDL-C mg/dL & $108.3 \pm 29.6$ & $109.2 \pm 32.1$ & 0.400 & $109.6 \pm 30.9$ & $130.5 \pm 30.7$ & $<0.001$ \\
\hline HDL-C mg/dL & $45.3 \pm 16.9$ & $45.7 \pm 14.1$ & 0.073 & $48.0 \pm 19.7$ & $51.3 \pm 13.7$ & $<0.001$ \\
\hline TC:HDL-C ratio & $4.1 \pm 0.9$ & $4.1 \pm 1.1$ & 0.980 & $4.0 \pm 1.0$ & $4.2 \pm 1.0$ & 0.001 \\
\hline LDL-C/HDL-C ratio & $2.5 \pm 0.7$ & $2.5 \pm 0.9$ & 0.841 & $2.4 \pm 0.8$ & $2.6 \pm 0.7$ & 0.002 \\
\hline \multicolumn{7}{|l|}{ Lipid levels out range (\%) } \\
\hline $\mathrm{TG}(\geq 150 \mathrm{mg} / \mathrm{dL})$ & 14.6 & 23.9 & 0.2082 & 23.9 & 28.9 & 0.4476 \\
\hline $\mathrm{TC}(\geq 200 \mathrm{mg} / \mathrm{dL})$ & 24.7 & 25.4 & 0.9252 & 25.9 & 63.2 & $<0.001$ \\
\hline LDL-C ( $\geq 130 \mathrm{mg} / \mathrm{dL})$ & 23.8 & 24.3 & 0.9085 & 26.2 & 56.0 & $<0.001$ \\
\hline TC:HDL-C ratio ( $\geq 4.5$ for men; $\geq 4.0$ for women) & 37.5 & 34.3 & 0.8114 & 31.5 & 39.6 & 0.2393 \\
\hline LDL-C:HDL-C ratio ( $\geq 3.0$ for men; $\geq 2.5$ for women) & 32.5 & 32.9 & 0.8982 & 30.8 & 32.1 & 0.9342 \\
\hline
\end{tabular}

Statistically significant differences are shown in bold.

HDL-C: HDL Cholesterol; LDL-C: LDL Cholesterol; TC: Total Cholesterol; TG: Triglycerides; WK48: Week 48 
In those patients with a lipid-lowering prescription $(n=21,13.9 \%)$, only 10 patients $(47.6 \%)$ showed an adherence of $\geq 90 \%$ to lipid-modifying agents. TC levels were significantly different among patients with an optimal and suboptimal adherence to lipid-lowering drugs after 48 weeks of EVG/c/FTC/TDF $(194.9 \pm 26.3$ vs $252.4 \pm 47.1, P=0.008$; Table 3). In patients with an optimal lipid-lowering drug adherence, significant differences were still found between basal TC and 48 weeks after beginning of EVG/c/FTC/TDF $(218.3 \pm 18.6$ vs $194.9 \pm 26.3, P=0.043$; Table 4).

Table 3. Lipid profiles after 48 weeks of study treatment in patients with and without optimal adherence to lipid-lowering treatment

\begin{tabular}{|c|c|c|c|c|c|c|}
\hline \multirow{2}{*}{$\begin{array}{l}\text { Naïve \& experienced } \\
\text { patients }\end{array}$} & \multicolumn{3}{|c|}{$\mathrm{EVG} / \mathrm{c} / \mathrm{FTC} / \mathrm{TDF}(n=21)$} & \multicolumn{3}{|c|}{ EVG/c/FTC/TAF $(n=54)$} \\
\hline & $\begin{array}{l}\geq 90 \% \text { Adherence } \\
(n=10)\end{array}$ & $\begin{array}{l}<90 \% \text { Adherence } \\
(n=11)\end{array}$ & $\begin{array}{l}P- \\
\text { value }\end{array}$ & $\begin{array}{l}\geq 90 \% \text { Adherence } \\
(n=34)\end{array}$ & $\begin{array}{l}<90 \% \text { Adherence } \\
(n=20)\end{array}$ & $\begin{array}{l}P- \\
\text { value }\end{array}$ \\
\hline \multicolumn{7}{|l|}{ Lipid levels (mean \pm SD) } \\
\hline $\mathrm{TG} \mathrm{mg} / \mathrm{dL}$ & $127.7 \pm 34.6$ & $173.4 \pm 111.9$ & 0.515 & $159.0 \pm 71.8$ & $134.5 \pm 55.7$ & 0.163 \\
\hline $\mathrm{TC} \mathrm{mg} / \mathrm{dL}$ & $194.8 \pm 26.3$ & $252.3 \pm 47.0$ & 0.008 & $220.5 \pm 47.6$ & $242.5 \pm 78.6$ & 0.537 \\
\hline LDL-C mg/dL & $126.0 \pm 26.9$ & $156.1 \pm 22.1$ & 0.065 & $139.6 \pm 43.2$ & $150.8 \pm 40.4$ & 0.460 \\
\hline HDL-C mg/dL & $42.6 \pm 6.5$ & $44.4 \pm 5.9$ & 0.587 & $49.6 \pm 14.9$ & $47.4 \pm 12.7$ & 0.860 \\
\hline $\begin{array}{l}\mathrm{TC}: \mathrm{HDL}-\mathrm{C} \\
\text { ratio }\end{array}$ & $4.6 \pm 1.0$ & $5.4 \pm 0.9$ & 0.104 & $4.7 \pm 1.2$ & $5.2 \pm 2.0$ & 0.699 \\
\hline $\begin{array}{l}\text { LDL-C/HDL-C } \\
\text { ratio }\end{array}$ & $3.0 \pm 0.9$ & $3.5 \pm 0.2$ & 0.233 & $3.0 \pm 1.0$ & $3.5 \pm 1.4$ & 0.367 \\
\hline
\end{tabular}

$\geq 90 \%$ dispensations registered in electronic clinical history of the patient was considered optimal adherence. Statistically significant differences are shown in bold.

HDL-C: HDL Cholesterol; LDL-C: LDL Cholesterol; TC: Total Cholesterol; TG: Triglycerides

Table 4. Changes in lipid profiles after 48 weeks of study treatment in patients with optimal adherence to lipid-lowering treatment

\begin{tabular}{|c|c|c|c|c|c|c|}
\hline \multirow{2}{*}{ Naïve \& experienced patients } & \multicolumn{3}{|c|}{$\mathrm{EVG} / \mathrm{c} / \mathrm{FTC} / \mathrm{TDF}(n=10)$} & \multicolumn{3}{|c|}{$\mathrm{EVG} / \mathrm{c} / \mathrm{FTC} / \mathrm{TAF}(n=34)$} \\
\hline & Basal & WK48 & $P$-value & Basal & WK48 & $P$-value \\
\hline \multicolumn{7}{|l|}{ Lipid levels (mean \pm SD) } \\
\hline $\mathrm{TG} \mathrm{mg} / \mathrm{dL}$ & $146.3 \pm 45.4$ & $127.7 \pm 34.6$ & 0.310 & $133.6 \pm 54.4$ & $159.0 \pm 71.8$ & 0.005 \\
\hline $\mathrm{TC} \mathrm{mg} / \mathrm{dL}$ & $218.2 \pm 18.6$ & $194.8 \pm 26.3$ & 0.043 & $199.6 \pm 34.9$ & $220.5 \pm 47.6$ & 0.006 \\
\hline LDL-C mg/dL & $146.0 \pm 11.0$ & $126.0 \pm 26.9$ & 0.063 & $125.5 \pm 34.2$ & $139.6 \pm 43.2$ & 0.032 \\
\hline HDL-C mg/dL & $42.4 \pm 5.5$ & $42.6 \pm 6.5$ & 0.116 & $47.3 \pm 16.8$ & $49.6 \pm 14.9$ & 0.106 \\
\hline TC:HDL-C ratio & $5.1 \pm 0.6$ & $4.6 \pm 1.0$ & 0.063 & $4.5 \pm 1.2$ & $4.7 \pm 1.2$ & 0.318 \\
\hline LDL-C/HDL-C ratio & $3.4 \pm 0.5$ & $3.0 \pm 0.9$ & 0.128 & $2.8 \pm 0.9$ & $3.0 \pm 1.0$ & 0.531 \\
\hline
\end{tabular}

$\geq 90 \%$ dispensations registered in electronic clinical history of the patient was considered optimal adherence. Statistically significant differences are shown in bold.

HDL-C: HDL Cholesterol; LDL-C: LDL Cholesterol; TC: Total Cholesterol; TG: Triglycerides; WK48: Week 48 


\subsection{Lipid profile variations in the EVG/c/FTC/TAF group}

Patients in the EVG/c/FTC/TAF treatment group showed significant variations in their lipid profile when we compared basal lipid values with those at 48 weeks after the start of the study treatment. When patients in lipid-lowering treatment were excluded (either those with prior [ $n=32]$ or during follow-up [ $n=22]$ lipid-lowering prescription) and basal lipid levels were compared with those at 48 weeks, statistically significant differences were observed in all the lipid profile evaluation parameters among experienced patients and in TC, LDL-C and HDL-C among naïve patients. A higher percentage of both naïve and experienced patients had lipid levels above the normal range after 48 weeks of EVG/c/FTC/TAF (Table 2).

Experienced patients with a previous ART based on TDF (63.1\%) had a worse lipid profile after 48 weeks of $\mathrm{EVG} / \mathrm{c} / \mathrm{FTC} / \mathrm{TAF}$ : triglycerides (TG; $122.6 \pm 67.3$ vs $152.9 \pm 130.3$, $P=0.0410)$, TC $(179.8 \pm 33.7$ vs $209.1 \pm 36.1, P<0.001)$, LDL-C $(109.3 \pm 30.5$ vs $129.8 \pm 29.8$, $P<0.001)$, HDL-C $(47.4 \pm 20.6$ vs $50.7 \pm 13.2, P=0.1751)$, TC:HDL-C ratio $(4.0 \pm 0.8$ vs $4.2 \pm 0.9, P=0.007)$ and LDL-C/HDL-C ratio $(2.5 \pm 0.6$ vs $2.6 \pm 0.6, P=0.044)$. However, in experienced patients with a previous ART based on other than TDF, only statistical differences were found in TC $(181.1 \pm 41.9$ vs $192.9 \pm 41.7, P=0.047)$, and LDL-C $(106.4 \pm 34.6$ vs $116.3 \pm 35.9, P=0.031)$.

The analysis performed in experienced patients with regard to the third active drug received before the start of EVG/c/FTC/TAF showed statistical differences in: TC $(185.9 \pm 43.7$ vs $217.0 \pm 37.1, P=0.0038)$, and LDL-C $(112.0 \pm 35.9$ vs $134.7 \pm 28.3, P=0.0082)$ among previous PI users $(27.0 \%)$; in TC $(183.8 \pm 33.4$ vs $208.2 \pm 39.1, P=0.0054)$, LDL-C $(114.4 \pm 26.6$ vs $131.0 \pm 33.6, P=0.0231)$, TC:HDL-C ratio ( $4.0 \pm 0.8$ vs $4.2 \pm 0.9, P=0.003)$, and LDL-C/HDL$\mathrm{C}$ ratio $(2.4 \pm 0.6$ vs $2.6 \pm 0.7, P=0.005)$ among previous NNRTI users $(28.6 \%)$; and in TG $(120.7 \pm 58.4$ vs $174.0 \pm 167.4, P=0.0329)$, TC $(173.7 \pm 31.4$ vs $205.0 \pm 37.8, P<0.001)$, and LDL-C $(104.9 \pm 30.0$ vs $127.6 \pm 30.2, P=0.0002)$ among previous INSTI $(44.4 \%)$ users.

About $62.9 \%$ of those patients with a lipid-lowering prescription showed an adherence of $\geq 90 \%$ to these drugs. No differences were observed in the lipid profile between adherent and nonadherent patients (Table 3). In patients with an optimal lipid-lowering adherence, significant differences were still found in TC, LDL-C and TG between basal and 48 weeks after $\mathrm{EVG} / \mathrm{c} / \mathrm{FTC} / \mathrm{TAF}$ prescription $(199.6 \pm 34.9$ vs $220.5 \pm 47.6, \quad P=0.006 ; 125.5 \pm 34.3$ vs $139.6 \pm 43.2, P=0.032 ; 133.7 \pm 54.4$ vs $159.1 \pm 71.9, P=0.005$, respectively; Table 4$)$.

\subsection{Lipid profile variations between groups}

Similar baseline lipid levels were seen in the two study groups in both naïve and experienced patients, both when considering the entire study population and when excluding those patients with lipid-lowering drug prescription (Table 5). The lipid levels of EVG/c/FTC/TDF and $\mathrm{EVG} / \mathrm{c} / \mathrm{FTC} / \mathrm{TAF}$ that showed differences at week 48 included TC $(183.0 \pm 28.6$ vs $209.6 \pm 35.5$, $P=0.0055)$, LDL-C $(112.4 \pm 21.1$ vs $132.1 \pm 31.3, P=0.0145)$, and HDL-C $(43.5 \pm 14.0$ vs $53.3 \pm 12.6, P=0.0105)$ among naïve; and TC $(177.5 \pm 36.6$ vs $208.9 \pm 38.0, P<0.0001)$, LDL-C $(109.2 \pm 32.1$ vs $130.5 \pm 30.7, P<0.001)$, and HDL-C $(45.7 \pm 14.1$ vs $51.3 \pm 13.7, P=0.0083)$ among experienced patients, excluding those patients with lipid-lowering drug prescriptions (Table 5). 
Table 5. Basal and After 48 weeks comparison between EVG/c/FTC/TDF versus EVG/c/FTC/TAF, excluding patients with lipid-lowering treatment prescription

\begin{tabular}{|c|c|c|c|c|c|c|}
\hline \multirow{2}{*}{$\begin{array}{l}\text { Lipid levels } \\
(\text { mean } \pm \text { SD) }\end{array}$} & \multicolumn{3}{|l|}{ BASAL } & \multicolumn{3}{|l|}{ WK48 } \\
\hline & $\begin{array}{l}\text { EVG/c/FTC/TDF } \\
(\mathrm{n}=130)\end{array}$ & $\begin{array}{l}\text { EVG/c/FTC/TAF } \\
(n=179)\end{array}$ & $\begin{array}{l}P- \\
\text { value }\end{array}$ & $\begin{array}{l}\text { EVG/c/FTC/TDF } \\
(\mathrm{n}=130)\end{array}$ & $\begin{array}{l}\text { EVG/c/FTC/TAF } \\
(\mathrm{n}=179)\end{array}$ & $\begin{array}{l}P \text { - } \\
\text { value }\end{array}$ \\
\hline \multicolumn{7}{|l|}{ Naïve patients } \\
\hline TG mg/dL & $115.5 \pm 56.4$ & $125.8 \pm 59.0$ & 0.4952 & $143.0 \pm 106.6$ & $127.7 \pm 69.7$ & 0.5655 \\
\hline $\mathrm{TC} \mathrm{mg} / \mathrm{dL}$ & $159.8 \pm 31.9$ & $173.3 \pm 44.8$ & 0.1992 & $183.0 \pm 28.6$ & $209.6 \pm 35.5$ & 0.0055 \\
\hline LDL-C mg/dL & $100.5 \pm 22.0$ & $109.7 \pm 40.5$ & 0.2821 & $112.4 \pm 21.1$ & $132.1 \pm 31.3$ & 0.0145 \\
\hline HDL-C mg/dL & $37.1 \pm 13.8$ & $43.0 \pm 8.2$ & 0.0750 & $43.5 \pm 14.0$ & $53.3 \pm 12.6$ & 0.0105 \\
\hline TC:HDL-C ratio & $4.6 \pm 1.1$ & $4.1 \pm 0.9$ & 0.1008 & $4.4 \pm 1.0$ & $4.1 \pm 1.1$ & 0.3256 \\
\hline $\begin{array}{l}\text { LDL-C/HDL-C } \\
\text { ratio }\end{array}$ & $2.9 \pm 0.8$ & $2.5 \pm 0.9$ & 0.1586 & $2.7 \pm 0.7$ & $2.6 \pm 0.9$ & 0.6745 \\
\hline \multicolumn{7}{|c|}{ Experienced patients } \\
\hline $\mathrm{TG} \mathrm{mg} / \mathrm{dL}$ & $114.8 \pm 58.0$ & $120 \pm 64.2$ & 0.4883 & $121.6 \pm 67.9$ & $148.9 \pm 123.5$ & 0.0546 \\
\hline $\mathrm{TC} \mathrm{mg} / \mathrm{dL}$ & $176.6 \pm 36.1$ & $179.9 \pm 35.8$ & 0.5195 & $177.5 \pm 36.6$ & $208.9 \pm 38.0$ & $<0.001$ \\
\hline LDL-C mg/dL & $108.3 \pm 29.6$ & $109.6 \pm 30.9$ & 0.7664 & $109.2 \pm 32.1$ & $130.5 \pm 30.7$ & $<0.001$ \\
\hline HDL-C mg/dL & $45.3 \pm 16.9$ & $48.0 \pm 19.7$ & 0.3210 & $45.7 \pm 14.1$ & $51.3 \pm 13.7$ & 0.0083 \\
\hline TC:HDL-C ratio & $4.1 \pm 0.9$ & $4.0 \pm 1.0$ & 0.5334 & $4.1 \pm 1.1$ & $4.2 \pm 1.0$ & 0.4492 \\
\hline $\begin{array}{l}\text { LDL-C/HDL-C } \\
\text { ratio }\end{array}$ & $2.5 \pm 0.7$ & $2.4 \pm 0.8$ & 0.5318 & $2.5 \pm 0.9$ & $2.6 \pm 0.7$ & 0.4387 \\
\hline
\end{tabular}

Statistically significant differences are shown in bold

HDL-C: HDL Cholesterol; LDL-C: LDL Cholesterol; TC: Total Cholesterol; TG: Triglycerides; WK48: Week 48

Prescription of lipid-lowering drugs in naïve patients was similar for both the EVG/c/FTC/TAF $(7.1 \%)$ and $\mathrm{EVG} / \mathrm{c} / \mathrm{FTC} / \mathrm{TDF}(6.2 \%)$ groups $(P=1.000)$. Experienced patients in treatment with $\mathrm{EVG} / \mathrm{c} / \mathrm{FTC} / \mathrm{TAF}$ were more likely to receive a new lipid-lowering prescription compared to those receiving EVG/c/FTC/TDF (11.9\% vs $4.7 \%, P=0.0468)$.

During follow-up, 14 patients in the EVG/c/FTC/TDF group (9.2\%) and 10 patients in the EVG/c/FTC/TAF group (4.2\%) discontinued treatment due to adverse events (AE; $P=0.0489$ ): gastrointestinal discomfort $(3.3 \%$ vs $0.8 \%, P=0.1171)$, alterations of renal function $(2.6 \%$ vs $0.0 \%, P=0.0233)$, events related to neuropsychiatric disturbances $(2.0 \%$ vs $0.8 \%, P=0.3857)$, headache and arthralgia $(1.3 \%$ vs $0.0 \%, P=0.1540)$, and hyperlipidaemia $(0.0 \%$ vs $2.6 \%$, $P=0.0854$; Table 6). Patients who took longer to discontinue treatment due to adverse effects were those in whom hyperlipidaemia was manifested (429.6 \pm 109.5 days), followed by patients with alterations of renal function (174.5 \pm 114.7 days), gastrointestinal discomfort (141.0 \pm 124.7 days), and neuropsychiatric disturbances (67.6 \pm 66.0 days). 
Table 6. Adverse events leading to study drug discontinuation

\begin{tabular}{llll}
\hline & EVG/c/FTC/TDF $(n=151)$ & EVG/c/FTC/TAF $(n=233)$ & $P$-value \\
\hline Any adverse event & $14(9.2 \%)$ & $10(4.2 \%)$ & 0.0489 \\
Gastrointestinal discomfort & $5(3.3 \%)$ & $2(0.8 \%)$ & 0.1171 \\
Alterations of renal function & $4(2.6 \%)$ & $0(0.0 \%)$ & 0.0233 \\
Neuropsychiatric disturbances & $3(2.0 \%)$ & $2(0.8 \%)$ & 0.3857 \\
Headache and arthralgia & $2(1.3 \%)$ & $0(0.0 \%)$ & 0.1540 \\
Hyperlipidaemia & $0(0.0 \%)$ & $6(2.6 \%)$ & 0.0854 \\
\end{tabular}

In the follow-up period, no differences were found in the number of patients who suffered an acute coronary syndrome $(0.6 \%$ in the $\mathrm{EVG} / \mathrm{c} / \mathrm{FTC} / \mathrm{TDF}$ group vs $1.2 \%$ in the EVG/c/FTC/TAF group, $P=0.999)$. Two patients in both groups died during follow-up $(P=0.6246)$; these deaths were not related to antiretroviral treatment or cardiovascular events.

A univariate analysis of risk factors for lipid-lowering prescription was performed considering age, gender, ethnic origin, routes of HIV transmission, HBV and HCV coinfection, treatment experience (naïve vs experienced), previous ART (TDF and PI, NNRTI or INSTI), current ART (EVG/c/FTC/TDF or EVG/c/FTC/TAF), number of cardiovascular risk factors and mean lipid profile in the first 48 weeks of the study treatment.

Age (odds ratio 1.04 [95\% confidence interval (CI) 1.00-1.08]; $P=0.033$ ), especially in those patients between 41 and 60 years old (5.71 [95\% CI 1.32-24.63]; $P=0.019$ ) and the number of cardiovascular risk factors $(1.81$ [95\% CI 1.13-2.90]; $P=0.0013)$ were associated with an increased risk of lipid-lowering prescription in patients treated with both EVG/c/FTC/TDF and EVG/c/FTC/TAF. In the multivariate analysis, only the number of cardiovascular risk factors (1.66 [95\% CI 1.01-2.72]; $P=0.043$ ) was recognised as an independent predictor of lipid-lowering prescription after adjusting for age, gender and current ART for patients treated with both EVG/c/FTC/TDF and EVG/c/FTC/TAF.

For patients in treatment with EVG/c/FTC/TAF, only the mean TC:HDL-C ratio in the first 48 weeks of the study treatment was associated with a more likely lipid-lowering prescription; indeed, this was shown by univariate analysis (1.9 [95\% 1.3-2.9]; $P=0.001)$ as well as multivariate analysis (1.6 [95\% CI 1.12-2.52]; $P=0.011)$ after adjusting for age and number of cardiovascular risk factors.

\section{DISCUSSION}

This study provides the first experience in real clinical practice regarding lipid profile alterations in patients being treated with EVG/c/FTC/TAF. Our findings show that this fixed combination had a negative influence on the lipid profile after 48 weeks' treatment, both in naïve and in experienced patients. This worsening of the lipid parameters has not been observed during the treatment with the EVG / c / FTC combination with tenofovir disoproxil fumarate. These unexpected results in the EVG/c/FTC/TAF group show how the lipid profile of patients varies, providing more data than has previously been published by clinical trials. 
Over the last three years, several studies have compared TDF with TAF regimens in terms of efficacy and safety, some of them in combination with EVG/c/FTC. ${ }^{19,21-25}$ In those studies of both treatment-naïve and suppressed patients switching to regimens based on TAF, the drug seems to have a minimum effect on the lipid profile. In the two blinded and controlled studies in treatmentnaïve patients, ${ }^{19,}{ }^{22}$ greater lipid concentrations (TG, TC, HDL-C and LDL-C) were seen in the EVG/c/FTC/TAF group compared to the EVG/c/FTC/TDF group $(P<0.001)$ at week 48 , and the authors relate this to significant reductions in plasma tenofovir concentrations with TAF. These results are similar to what we observed in our naïve patients when we compared the two treatment groups. As in clinical trials, we also found no differences in the TC:HDL-C ratio (associated with cardiovascular disease risk) between groups or in cardiovascular or cerebrovascular events, nor in the proportion of participants initiating lipid-modifying agents in naïve patients, although the proportion in our study $(7.1 \%)$ was higher than in clinical trials $(3.6 \%)$ for patients given EVG/c/FTC/TAF.

There exist other clinical trials in which TAF/FTC has also been evaluated against TDF/FTC in naïve patients combined with other than EVG/c. ${ }^{25,}{ }^{28}$ Mills et al saw greater increases in the fasting lipid parameters (TG, TC, LDL-C and HDL-C) in the TAF group compared with the TDF group at week 48, while in the Sax et al study, changes in fasting lipids were similar between regimens. There were no differences in the TC:HDL-C ratio, treatment-related cardiovascular events, or in the number of participants who were started on lipid-lowering medications during the study; with this said, however, in the Mills et al study, a similar percentage of these drugs was prescribed in the TAF group compared to that of our study $(6.8 \%)$.

Among treatment-experienced patients, both in clinical trials with EVG/c/FTC/TAF ${ }^{24}$ and FTC/TAF combined with another third agent, ${ }^{21,23}$ lipid values increased from baseline in the TAF group while remaining stable in the TDF group at weeks 48 and 96; however, the authors concluded that median changes in lipid values were minimal from a clinical standpoint and the median changes in TC:HDL-C ratio were similar ${ }^{21,23}$ or minimal. ${ }^{24}$ Our data are in contrast with those reported in trials and highlight that experienced patients encountered an important worsening of their lipid profile and a significant change in TC:HDL-C and LDL-C:HDL-C ratios. Furthermore, a high percentage of patients in the EVG/c/FTC/TAF group exceeded values above the normal range of cholesterol (40\%) and LDL-C (30\%) after 48 weeks of treatment. It is for this reason that we also saw in our study that these patients had a higher percentage of lipid-lowering prescription than the EVG/c/FTC/TDF group (11.9\% vs $4.7 \%, P=0.0468$ ), which also contrasts with what was reported in clinical trials ( $4 \%$ in both groups in one of the studies, ${ }^{21}$ and FTC/TAF $7.2 \%$ vs FTC/TDF $6.4 \%, P=0.76$ in the other clinical trial ${ }^{23}$ ). Reported frequency of lipid-related or cardiovascular adverse events was similar between the two groups, similar to what was observed in our study.

In all these clinical trials, the authors conclude that the lower concentrations of tenofovir in plasma from TAF when compared with TDF, and the lipid-lowering effect of tenofovir, may explain the statistically significant increases in lipid profile in the TAF group compared with the TDF group. Changes in lipid levels were reported to be of minimal clinical relevance and were not deemed to be an adverse effect of TAF but rather an effect of an absence of high plasma tenofovir concentrations. Treatment with TDF has consistently been associated with lower lipids compared with other regimens in treatment-naïve or virologically suppressed individuals. ${ }^{16,17,24}$

Switching TDF to TAF leads to an increase in lipids and, conversely, lipid parameters improve when HIV-positive individuals switch to TDF; indeed, this was seen in the six patients who discontinued EVG/c/FTC/TAF due to hyperlipidaemia and returned to their previous treatment, which was based on TDF. Adding TDF to a fully suppressive regimen decreases TC by $36.5 \mathrm{mg} / \mathrm{dL}$ and LDL-C by $20 \mathrm{mg} / \mathrm{dL} ;{ }^{17}$ very similar increases values were observed in our study when experienced patients changed to $\mathrm{EVG} / \mathrm{c} / \mathrm{FTC} / \mathrm{TAF}$. 
All clinical trials suggested that although overall safety was similar, EVG/C/FTC/TAF had a favourable long-term renal and bone safety profile. For these reasons, recent HIV treatment guidelines have either replaced TDF with TAF or included both as part of recommended initial regimens, and advised TAF or abacavir in patients who cannot receive TDF due to renal dysfunction or osteoporosis. The recommendations in clinical guidelines aim to minimise the risk factors and the development of renal and bone events in these patients. However, it is important to keep in mind that although the clinical trials concluded that changes from baseline in fasting lipid concentrations were generally similar between groups and not deemed clinically relevant, in reallife experience we observed an increase in lipid levels, a significant increase in TC:HDL-C (associated with cardiovascular disease risk) and an increase in lipid-lowering prescription, which could give rise to an increase in cardiovascular risk. These data should also be evaluated when recommendations are made by clinical practice guidelines, especially knowing that the HIV population is more susceptible to cardiovascular risk than the general population, and that the use of TDF has been linked to reduced lipid levels in HIV patients when compared with other nucleoside reverse transcriptase inhibitors.

Among a large cohort of HIV-infected patients actively using antiretrovirals between 2002 and $2011,{ }^{14}$ TDF use was strongly associated with lower risk of heart failure incidents. Compared with never users of TDF, current users of TDF and patients whose initial regimen included TDF had reductions in heart failure risk ranging from $30 \%$ to $50 \%$. One of the mechanisms suggested by the authors for a potential protective effect could be TDF's lipid-lowering effects, which could create a potentially beneficial reduction in atherosclerosis and subsequent coronary artery disease.

Cardiovascular disease is already an important contributor to overall morbidity and has become one of the leading causes of death among HIV-infected patients in countries with established antiretroviral treatment programmes. Compared with the general population, people living with HIV have a 1.5- to 2-times increased risk of cardiovascular disease. ${ }^{7,14,29-31}$ Fontenla et al estimated that over three quarters had a minimum of one cardiovascular risk factor2 with dyslipidaemia and smoking being the most frequent ones, similar to what we observed in our study population. Smoking has been found to be associated with a greater risk of myocardial infarction in the HIV-infected population than in the general population, ${ }^{31}$ and nearly $50 \%$ of our study population were smokers. Dyslipidaemia is considered a major risk factor for cardiovascular disease. The prevalence of dyslipidaemia in large HIV cohort studies has ranged from $31 \%$ to $81 \%$ based on various definitions used for dyslipidaemia. ${ }^{31}$ In our study, more than $25 \%$ of the patients in both groups had baseline dyslipidaemia, which contrasts significantly with the values at 48 weeks in the EVG/c/FTC/TAF group (63\%).

A prospective cohort (APROCO/COPILOTE Cohort Study ${ }^{32}$ ) with a median follow-up of 7.3 years reported a higher incidence of non-AIDS events than that of antiretroviral treatmentrelated and AIDS-defining events (10.5, 3.6 and 2.6 per 100 patient years, respectively). Bacterial infections were the most frequent non-AIDS events $(23.4 \%)$, followed by non-AIDS-defining malignancies and cardiovascular events (both 9.5\%). Based on data from the APROCO/COPILOTE Cohort Study Factors, the rate of patients with cardiovascular events was higher than that of patients experiencing ART clinical events.

As expected, HIV patients in our study with more risk factors and a higher age were more likely to receive a new lipid-lowering prescription, as has been seen in other studies. ${ }^{31}$ Surprisingly, in the EVG/c/FTC/TAF group, it seemed that neither age nor number of cardiovascular risk factors influenced the prescription of lipid-lowering drugs, although the TC:HDL-C ratio did; indeed, this implies that even young patients or those with few cardiovascular disease risk factors will receive these lipid-lowering drugs if there is an elevation of the TC:HDL-C ratio values. 
Lipid-lowering drugs, and statins in particular, are not free from adverse events. The most common event is myotoxicity, which is present in approximately $10 \%-25 \%$ of patients undergoing treatment, but commonly associated with muscle weakness, elevated liver enzymes and an accelerated diabetes mellitus process. ${ }^{33}$ Therefore, statins should be carefully prescribed; this is also important because they may present drug-drug interaction with ART. It must also be taken into account that although statins are prescribed, there are barriers to the successful controlling of dyslipidaemia, which could include non-adherence, perceived drug side effects, polypharmacy, costs of statins, suboptimal physician provider/patient relationships, and overestimation of the effect of diet control. ${ }^{4,31,34}$ Around $40 \%$ of the patients in our study were non-adherent to lipidlowering drugs; therefore, there could be a problem derived from not achieving therapeutic success, which is necessary if the patient has elevated lipid levels.

Several factors may probably explain the conflicting results observed between trials and our data. Those who might partially explain these findings is the older population in our study (46 years) compared to that in the clinical trials ${ }^{19,25,28}$ (31-35 years), and the observational research design. Although there were differences between the groups in two baseline variables, one of them, ethnic origin, was considered in the univariate analysis of risk factors for lipidlowering prescription, with the results revealing that it had no influence. The higher rate of RNAHIV basal $<50$ copies/mL observed in the EVG/c/FTC/TAF group might reflect a higher adherence to ART, which could have an impact on the lipid values at WK48. However, since no differences at baseline in the lipid profile were observed between groups, the impact of these baseline differences in the lipid values at WK48, if they exist, should be very low. The main limitation of the study was missing information regarding management of dyslipidaemia using lifestyle modifications such as dietary changes and exercise; indeed, this may explain why some patients were not prescribed lipid-lowering drugs. Other limitations included the small sample size, the single-centre nature of the study, and the retrospective observational design, which might have introduced uncontrolled bias.

In summary, in this study, lipid levels increased from baseline in the EVG/C/FTC/TAF group while remaining stable in the EVG/c/FTC/TDF group after 48 weeks of treatment, both in naïve and experienced patients. As a result, a higher rate of patients had lipid levels out of range and a new prescription of lipid-modifying drug was needed in the EVG/c/FTC/TAF group. Age and higher cardiovascular risk factors were predictors of receiving a new lipid-lowering drug prescription for the whole study population. However, for patients in the EVG/c/FTC/TAF group, mean TC:HDL-C ratio in the first 48 weeks of treatment was the predictor of initiation of a lipidlowering drug regardless of the age and cardiovascular risk factors of the patient.

Compared with EVG/c/FTC/TDF, EVG/c/FTC/TAF seemed to have the advantages of improving renal and bone parameters based on clinical trials. The clinical significance of this observed change in lipid levels is unclear, but it is necessary to take it into account, because the ageing of HIV-infected patients on ART is associated with a high prevalence of comorbidities and risk factors that necessitate careful monitoring, and adequate control of chronic diseases, as well as the risk factors of these diseases. This observation requires robust exploration in appropriately designed studies and powerful cohorts with more patients. 


\section{DISCLOSURE STATEMENT}

Dr CID-SILVA reports grants from Fondo de Investigación Sanitaria, and grants from Fundación Profesor Novoa Santos, during the conducting of the study. Dr Fernandez-Bargiela, Dr Margusino-Framiñán, Dr Balboa-Barreiro, Dr Mena-De-Cea, Dr López-Calvo, Dr VázquezRodríguez, Dr Martín-Herranz, Dr Míguez-Rey: has nothing to disclose. Dr POVEDA reports grants from Fondo de Investigación Sanitaria and grants from Fundación Profesor Novoa Santos during the conducting of the study; grants, personal fees and non-financial support from JANSSEN CILAG, grants and non-financial support from GILEAD SCIENCES, personal fees and non-financial support from MERCK SHARP \&DOHME, and non-financial support from ViiV Healthcare, outside the submitted work. Dr Castro-Iglesias has nothing to disclose.

\section{REFERENCES}

1. Deeks, SG, Lewin, SR, Havlir, DV. The end of AIDS: HIV infection as a chronic disease. Lancet 2013; 382( 9903): 1525- 1533.

2. Fontela, C, Castilla, J, Juanbeltz, R, Martínez-Baz, I, Rivero, M, O'Leary, A, et al. Comorbidities and cardiovascular risk factors in an aged cohort of HIV-infected patients on antiretroviral treatment in a Spanish hospital in 2016. Postgrad Med 2018; 130: 317- 324.

3. McGettrick, P, Barco, EA, Mallon, P. Ageing with HIV. Healthcare 2018; 6: E17.

4. Morillo-Verdugo, R, Blanco Ramos, JR, Abdel-Kader Martín, L, Álvarez de Sotomayor, M. The challenge of aging and pharmacoterapeutic complexity in the HIV + patient. Farm Hosp 2018; 42: 120- 127.

5. Maggi, P, Biagio, A, Rusconi, S, Cicalini, S, D'Abbraccio, M, d'Ettorre, G, et al. Cardiovascular risk and dyslipidemia among persons living with HIV: a review. BMC Infect Dis 2017; 17: 551.

6. Deeks, SG. HIV infection, inflammation, immunosenescence, and aging. Annu Rev Med 2011; 62: 141- 155 .

7. Zanetti, HR, Roever, L, Gonçalves, A, Resende, ES. Human Immunodeficiency Virus Infection, Antiretroviral Therapy, and Statin: a Clinical Update. Curr Atheroscler Rep 2018; 20 : 9.

8. Panel on Antiretroviral Guidelines for Adults and Adolescents. Guidelines for the use of antiretroviral agents in HIV-1-infected adults and adolescents. Department of Health and Human Services, May 30, 2018.

http://www.aidsinfo.nih.gov/ContentFiles/AdultandAdolescentGL.pdf. Accessed on 03 August 2018.

9. Panel Members of European AIDS Clinical Society (EACS). European Guidelines for treatment of HIV-positive adults in Europe version 9.0. EACS, October 2017.

http://www.eacsociety.org/files/guidelines_9.0-english.pdf. Accessed on 03 August 2018.

10. Panel de expertos de GeSIDA y Plan Nacional sobre el Sida. Documento de consenso de GESIDA/Plan nacional sobre el sida respecto al tratamiento antirretroviral en adultos infectados por el virus de la inmunodeficiencia humana (Actualización enero 2018). SEIMC, January 2018. http://gesida-seimc.org/wp-content/uploads/2018/01/gesida_TAR_adultos_v3-1.pdf. Accessed on 03 August 2018.

11. Gallant, JE, Staszewski, S, Pozniak, AL, DeJesus, E, Suleiman, JM, Miller, MD, et al. Efficacy and safety of tenofovir DF vs stavudine in combination therapy in antiretroviral-naive patients: a 3-year randomized trial. JAMA 2004; 292: 191- 201.

12. Arribas, JR, Pozniak, AL, Gallant, JE, Dejesus, E, Gazzard, B, Campo, RE, et al. Tenofovir disoproxil fumarate, emtricitabine, and efavirenz compared with zidovudine/lamivudine and efavirenz in treatment-naive patients: 144-week analysis. J Acquir Immune Defic Syndr 2008; 47: 74- 78 .

13. Squires, K, Pozniak, AL, Pierone, G, Steinhart, CR, Berger, D, Bellos, NC, et al. Tenofovir disoproxil fumarate in nucleoside-resistant HIV-1 infection: a randomized trial. Ann Intern Med 2003; 139: 313- 320.

14. Chen, R, Scherzer, R, Hsue, PY, Jotwani, V, Estrella, MM, Horberg, MA, et al. Association of tenofovir use with risk of incident heart failure in HIV-infected patients. J Am Heart Assoc 2017; 6: 1- 11. 
15. Fernández Lisón, LC, Vázquez Domínguez, B, Rodríguez Gómez, FJ, Hevia Alonso, A, Pujol de la Llave E, . Use study of tenofovir DF in highly active anti-retroviral therapy. An Med Interna 2006; 23: 573- 576.

16. Santos, JR, Saumoy, M, Curran, A, Bravo, I, Llibre, JM, Navarro, J, et al. The lipid-lowering effect of tenofovir/emtricitabine: a randomized, crossover, double-blind, placebo-controlled trial. Clin Infect Dis 2015; 61: 403- 408.

17. Tungsiripat, M, Kitch, D, Glesby, MJ, Gupta, SK, Mellors, JW, Moran, L, et al. A pilot study to determine the impact on dyslipidemia of adding tenofovir to stable background antiretroviral therapy: ACTG 5206. AIDS 2010; 24: 1781- 1784.

18. Crane, HM, Grunfeld, C, Willig, JH, Mugavero, MJ, Rompaey, S, Moore, R, et al. Impact of NRTIs on lipid levels among a large HIV-infected cohort initiating antiretroviral therapy in clinical care. AIDS 2011; 25: 185- 195.

19. Sax, PE, Wohl, D, Yin, MT, Post, F, DeJesus, E, Saag, M, et al. Tenofovir alafenamide versus tenofovir disoproxil fumarate, coformulated with elvitegravir, cobicistat, and emtricitabine, for initial treatment of HIV-1 infection: two randomised, double-blind, phase 3, non-inferiority trials. Lancet 2015; 385: 2606- 2615.

20. Wang, H, Lu, X, Yang, X, Xu, N. The efficacy and safety of tenofovir alafenamide versus tenofovir disoproxil fumarate in antiretroviral regimens for HIV-1 therapy Meta-analysis. Medicine 2016; 95: e5146.

21. Gallant, JE, Daar, ES, Raffi, F, Brinson, C, Ruane, P, DeJesus, E, et al. Efficacy and safety of tenofovir alafenamide versus tenofovir disoproxil fumarate given as fixed-dose combinations containing emtricitabine as backbones for treatment of HIV-1 infection in virologically suppressed adults:a randomised, double-blind, active-controlled phase 3 trial. Lancet HIV 2016; 3: e158-e165.

22. Arribas, JR, Thompson, M, Sax, PE, Haas, B, McDonald, C, Wohl, DA, et al. Randomized, double-blind comparison of tenofovir alafenamide (TAF) vs tenofovir disoproxil fumarate (TDF), each coformulated with elvitegravir, cobicistat, and emtricitabine (E/C/F) for initial HIV-1 treatment: Week 144 results. J Acquir Immune Defic Syndr 2017; 75: 211- 218.

23. Raffi, F, Orkin, C, Clarke, A, Slama, L, Gallant, J, Daar, E, et al. Long-term (96-Week) efficacy and safety after switching from tenofovir disoproxil fumarate to tenofovir alafenamide in HIV infected, virologically suppressed adults. J Acquir Immune Defic Syndr 2017; 75: 226- 231.

24. Mills, A, Arribas, JR, Andrade-Villanueva, J, DiPerri, G, Lunzen, J, Koenig, E, et al. Switching from tenofovir disoproxil fumarate to tenofovir alafenamide in antiretroviral regimens for virologically suppressed adults with HIV-1 infection: a randomised, active-controlled, multicentre, open-label, phase 3, non-inferiority study. Lancet Infect Dis 2016; 16: 43- 52.

25. Sax, PE, Pozniak, A, Montes, ML, Koenig, E, DeJesus, E, Stellbrink, HJ, et al. Coformulated bictegravir, emtricitabine, and tenofovir alafenamide versus dolutegravir with emtricitabine and tenofovir alafenamide, for initial treatment of HIV-1 infection(GS-US-380-1490):a randomised, double-blind, multicentre, phase 3, non-inferiority trial. Lancet 2017; 390: 2073- 2082.

26. Tveden-Nyborg, P, Bergmann, TK, Lykkesfeldt, J. Basic \& clinical pharmacology \& toxicology policy for experimental and clinical studies. Basic Clin Pharmacol Toxicol 2018; 123( 3): 233235.

27. Division of AIDS (DAIDS) Table for Grading the Severity of Adult and Pediatric Adverse Events Version 2.0 November 2014. Services, Division of AIDS National Institute of Allergy and Infectious Diseases National Institutes of Health US Department of Health and Human.

28. Mills, A, Crofoot, G, McDonald, C, Shalit, P, Flamm, JA, Gathe, J et al. Tenofovir Alafenamide versus tenofovir disoproxil fumarate in the first protease inhibitor-based single-tablet regimen for initial HIV-1 therapy: a randomized phase 2 study. J Acquir Immune Defic Syndr 2015; 69: $439-445$.

29. Currier, JS. Management of long-term complications of HIV disease: focus on cardiovascular disease. Top Antivir Med 2018; 25: 133- 137

30. McGettrick, PMC, Mallon, PWG. HIV and cardiovascular disease: defining the unmeasured risk. Lancet 2018; 5: e267- e269.

31. Levy, ME, Greenberg, AE, Magnus, M, Younes, N, Castel, A, on behalf of the DC Cohort Executive Committee. Evaluation of statin eligibility, prescribing practices, and therapeutic responses using ATP III, ACC/AHA, and NLA dyslipidemia treatment guidelines in a large urban cohort of HIV-infected outpatients. AIDS patient. Care and STDs 2018; 32: 58-69. 
32. Ferry, T, Raffi, F, Collin-Filleul, F, Dupon, M, Dellamonica, P, Waldner, A, et al. Uncontrolled viral replication as a risk factor for non-AIDS severe clinical events in HIV-infected patients on long-term antiretroviral therapy: APROCO/COPILOTE (ANRS CO8) cohort study. J Acquir Immune Defic Syndr 2009; 51: 407-415.

33. Lichtenstein, KA, Hart, RL, Wood, KC, Bozzette, S, Buchacz, K, Brooks, JT, et al. Statin use is associated with incident diabetes mellitus among patients in the HIV outpatient study. $J$ Acquir Immune Defic Syndr 2015; 69: 306- 311.

34. Jiménez Galán, R, Montes Escalante, IM, Morillo Verdugo, R. Influence of pharmacotherapy complexity on compliance with the therapeutic objectives for HIV+ patients on antiretroviral treatment concomitant with therapy for dyslipidemia. INCOFAR Project. Farm Hosp 2016; 40: 90- 96. 